\title{
The relationship of body mass index and waist-hip ratio with shift work among military personnel in 2016
}

\author{
Ghanbary Sartang A, MSc ${ }^{1}$, Ashnagar $\mathrm{M}, \mathrm{MSc}^{2 *}$, Habibi $\mathrm{E}, \mathrm{PhD}^{3}$, Nowrouzi I, $\mathrm{MSc}^{4}$, \\ ghasemi $\mathrm{H}, \mathrm{BSc}^{5}$ \\ 1- MSc in Occupational Health Engineering, School of Health, Isfahan University of Medical Sciences, Isfahan, Iran. \\ 2- MSc in Industrial Psychology, Bandar Abbas, Iran. 3-Professor in Occupational Health Engineering, School of Health, \\ Isfahan University of Medical Sciences, Isfahan, Iran. 4- Msc in petroleum Engineering, Omidiyeh Branch, Islamic Azad \\ University, Omidiyeh, Iran. 5- BSc in Petroleum Engineering, Omidiyeh Branch, Islamic Azad University, Omidiyeh, Iran.
}

\begin{abstract}
Received: September 2016, Accepted: November 2016

Background: Today, obesity is considered as a health problem that increases the risk of some diseases. Therefore, identifying the effective factors on obesity is of great importance. Shift work is one of the indicators for increased risk of obesity in society and also shift work may cause various health problems for workers in military organizations. The current study aimed to investigate the relationship between shift work, and body mass index (BMI) and waist-hip ratio (WHR) among military personnel in 2016.

Materials and Methods: This cross-sectional study was carried out on 100 male military personnel in Southern Iran in June-July 2016. The participants were divided into two groups based on their working schedule; shift work (50 personnel) and day work (50 personnel). The two groups were similar in terms of type of work. The subjects were selected through simple random sampling. The data collection tools consisted of a tape measure and a digital balance. Data analysis and comparison of BMI and WHR in the two groups were performed using descriptive statistics, one-way ANOVA, and Pearson correlation in SPSS.

Results: The findings revealed that mean body weight, waist circumference, hip circumference, BMI, and WHR were higher in shift workers than day workers. The findings of the current study showed that $81.6 \%$ of shift workers had a BMI of higher than $25 \mathrm{~kg} / \mathrm{m}^{2}$ and $80.3 \%$ of shift workers had a WHR of higher than $0.90 \mathrm{~m}$. Moreover, $86.2 \%$ of day workers had a BMI of less than $25 \mathrm{~kg} / \mathrm{m}^{2}$ and $83.1 \%$ of days workers had a WHR of less than $0.90 \mathrm{~m}$. The Pearson correlation coefficient for BMI $(\mathrm{r}=0.71)$ and WHR $(\mathrm{r}=0.64)$ in shift workers were higher than day workers.

Conclusions: The findings of this research showed that shift work increased the risk of overweight and obesity. Increased BMI and WHR are the cause of disease and require intervention measures (job rotation, sports activities, and avoidance of long duration of shift work) among shift workers.
\end{abstract}

Keywords: Body Mass Index, Waist-Hip Ratio, Shift Work, Military Personnel

\section{Introduction}

Shift work is any kind of work carried out outside the standard working day ( 7 am to 6 $\mathrm{pm})$. Shift work is considered one of the occupational stressor that is harmful to human health. Shift work is associated with many negative health effects, such as obesity. On the other hand, different and long shift work can endanger the physical and mental health of military personnel (1). Shift work can have various adverse effects on human productivity and quality of work life, thus affecting the physical and mental health, social security, and family life of individuals $(2,3)$. Longitudinal approaches on the impact of the changing work schedule (from day to night work or the reverse) may clarify the influence of work shift on the dynamics of increase in body mass index (BMI) over time. In a study,

\footnotetext{
* Corresponding author: Mehdi Ashnagar, MSc in Industrial Psychology, Bandar Abbas, Iran. Email: m.ashna63@yahoo.com
} 
Bekkers et al. observed the highest increase in BMI among workers who changed from daytime to shift work (4). Wang et al. concluded that shift work may cause various health problems for workers. A wide range of aspects of employees' life can be affected by shift work. It can result in cardiovascular problems, digestive problems, and decreased performance. Decreased performance is one of the detrimental effects of shift work (1). Saksvik et al. believe that while some employees develop serious problems due to shift work exposure, some others tolerate the exposure to shift work well (5). Today, obesity is considered as a health problem that increases the risk of some diseases. Overweight and obesity are defined as abnormal or excessive fat accumulation that may impair health, overweight and obesity is said to be the world's fifth leading cause of death (6). Many aspects of employees' life can be affected by shift work including physical and mental health, safety, social life, and work performance/effectiveness (7). Van Drongelen et al concluded overweight and obesity are serious threats to human health and is a risk factor for heart attack (8). Diseases caused by overweight and obesity include kidney stones, increase cholesterol and triglycerides that increase the risk of heart disease, diabetes and high blood pressure (9). Increase in weight and obesity is the result of changes in eating habits; thus, they are prevalent among shift workers. New findings show that disruption of the circadian clock can not only lead to obesity, but also increase the risk of diabetes and heart disease (10). Changes in circadian rhythms among shift workers is the cause of restlessness, irritability, bad mood, gastrointestinal tract disorders, and decreased sleep duration and work efficiency $(11,12)$. Shift workers individuals often suffer from sleep disorders due to their sleeping and waking cycle. In addition, the main cause of insomnia in shift workers is changes in the circadian rhythm $(13,14)$. Antunes showed that $62 \%$ of people suffer from sleep disorders and insomnia is the most common complaint of shift workers (15). Dorrian et al. concluded that shift work causes increases the body weight and this causes an increase in BMI and waist circumference. Shift workers are exposed to greater health risks compared with those who work standard hours. Those who work at night may be at risk of ill health because shift work can disrupt the circadian rhythms (internal clock) by interfering with the production of melatonin (16). Shift worker are exposed to physical and mental illnesses such as cardiovascular problems, depression, irritability, problems with co-workers, and digestive diseases more than others. Occupational risk factors are high in shift workers. Therefore, the current study aimed to investigate the relationship of BMI and waisthip ratio (WHR) with shift work among military personnel.

\section{Material and Methods}

This cross-sectional study was carried out on 100 male military personnel in Southern Iran in June-July 2016. The participants were divided into two groups based on their working schedule; day work (from 7 am to 4 $\mathrm{pm} ; \mathrm{N}=50$ ) and shift work (from $7 \mathrm{pm}$ to 7 am; $N=50$ ) (13). The two groups were similar in terms of type of work. The subjects were selected through simple random sampling. Data collection tools consisted of a tape measure with a precision of $1 \mathrm{~cm}$ and a digital balance (NBL 223e model) with a precision of 0.001 gr. Written consent forms were obtained from all those who accepted to participate in the study after receiving details about the study methods and objectives. Participants ensured that their information would remain anonymous and the data would be kept in a safe place and would not be used for any purposes other than for the present study. An approval was also obtained from the ethics committee. The inclusion criteria included lack of history of hypertension or other medical problems and 6 months experience of shift work. The exclusion criteria were consisted of pain or discomfort in various body organs, and 
unwillingness to participate in the study. BMI is calculated by dividing weight by height squared and expressed as $\mathrm{kg} / \mathrm{m}^{2}$. The range of BMI signifying underweight to obesity includes underweight: under $18.5 \mathrm{~kg} / \mathrm{m}^{2}$, normal weight: 18.5 to $25 \mathrm{~kg} / \mathrm{m}^{2}$, overweight: 25 to $30 \mathrm{~kg} / \mathrm{m}^{2}$, and obese: over $30 \mathrm{~kg} / \mathrm{m}^{2}$ (17). The WHR is calculated by dividing waist circumference by hip circumference. The range of WHR signifying normal weight to obesity includes normal weight: under $0.90 \mathrm{~m}$, overweight: 0.90 to $0.99 \mathrm{~m}$, obesity: over $1 \mathrm{~m}$ (18). In the present study, first, the subjects' heights were measured in terms of meter using a tape measure, then, their weight was measured in terms of $\mathrm{Kg}$ using a digital balance, and then, BMI was calculated [weight $(\mathrm{kg}) /$ height $\left.(\mathrm{m})^{2}\right]$. For measurement of WHR, first, waist circumference and hip circumference were measured in terms of $\mathrm{cm}$ using a tape measure, and then, WHR was calculated (waist circumference/hip circumference). Data analysis was performed using descriptive statistics, one-way ANOVA, and Pearson correlation in SPSS software (version 20, SPSS Inc., Chicago, IL, USA). All $P$ values of less than 0.05 were considered statistically significant.

\section{Results}

In terms of marital status, 42 participants were single (day work: 26 , shift work: 16 ), and 58 were married (day work: 24, shift work: 34 ). Demographic variables of age and work experience are presented in table 1.

Table 1: Demographic variables of age and work experience of 50 day work and 50 shift work personnel

\begin{tabular}{cccc}
\hline Variable & Shift & Mean \pm SD & Range \\
\hline \multirow{2}{*}{ Age (year) } & Day work & $36.00 \pm 3.84$ & $26-36$ \\
\cline { 2 - 4 } & Shift work & $37.00 \pm 2.45$ & $25-38$ \\
\hline \multirow{2}{*}{ Work experience (year) } & Day work & $12.16 \pm 2.62$ & $3-13$ \\
\cline { 2 - 4 } & Shift work & $13.84 \pm 3.71$ & $1-15$ \\
\hline
\end{tabular}

According to table 1, the average age and work experience of shift workers were higher than day workers.
The height, weight, waist circumference, hip circumference, BMI, and WHR of the participants are presented in table 2 .

Table 2: The height, weight, waist circumference, hip circumference, body mass index, and waist-hip ratio of participants

\begin{tabular}{cccc}
\hline Variable & Shift & Mean \pm SD & Minimum-maximum \\
\hline \multirow{2}{*}{ Height $(\mathbf{c m})$} & Day work & $184.00 \pm 2.04$ & $171-186$ \\
\cline { 2 - 4 } & Shift work & $181.00 \pm 4.35$ & $172-184$ \\
\hline \multirow{2}{*}{ Weight $(\mathbf{k g})$} & Day work & $79.60 \pm 4.26$ & $69-85$ \\
\cline { 2 - 4 } & Shift work & $84.07 \pm 7.17$ & $78-96$ \\
\hline \multirow{2}{*}{ Waist circumference $(\mathbf{c m})$} & Day work & $79.01 \pm 2.24$ & $75-81$ \\
\cline { 2 - 4 } & Shift work & $92.00 \pm 1.06$ & $80-95$ \\
\hline \multirow{2}{*}{ Hip circumference $(\mathbf{c m})$} & Day work & $84.22 \pm 1.09$ & $81-87$ \\
\cline { 2 - 4 } Body mass index $\left(\mathbf{k g} / \mathbf{m}^{\mathbf{2}}\right)$ & Shift work & $95.84 \pm 3.78$ & $86-97$ \\
\cline { 2 - 4 } & Day work & $23.07 \pm 1.26$ & $19.3-25.9$ \\
\hline \multirow{2}{*}{ Waist-hip ratio $(\mathbf{m})$} & Shift work & $27.09 \pm 1.94$ & $23.1-28.3$ \\
\cline { 2 - 4 } & Day work & $0.86 \pm 0.20$ & $0.77-0.91$ \\
\cline { 2 - 4 } & Shift work & $0.97 \pm 0.06$ & $0.85-0.98$ \\
\hline
\end{tabular}

According to table 2, mean body weight, waist circumference, hip circumference, BMI, and WHR of shift workers was higher than day workers. Table 3 shows the Pearson correlation coefficients of BMI and WHR of day and shift workers. 
Table 3: Pearson correlation coefficients of body mass index and waist-hip ratio of day and shift workers

\begin{tabular}{cccc}
\hline \multirow{2}{*}{ Variable } & Shift & $\begin{array}{c}\text { Pearson correlation } \\
(\mathbf{r})\end{array}$ & P \\
\hline \multirow{2}{*}{ Body mass index } & Day work & 0.31 & 0.010 \\
\cline { 2 - 4 } & Shift work & 0.71 & 0.001 \\
\hline \multirow{2}{*}{ Waist-hip ratio } & Day work & 0.22 & 0.010 \\
\cline { 2 - 4 } & Shift work & 0.64 & 0.001 \\
\hline
\end{tabular}

According to table 3, the Pearson correlation coefficient for BMI $(r=0.71)$ and WHR $(r=$ $0.64)$ of shift workers were higher than that of day workers. The classification of BMI and WHR of day and shift workers are presented in table 4.

Table 4: Body mass index and waist-hip ratio classification of day and shift workers

\begin{tabular}{|c|c|c|c|}
\hline Variable & Shift & Status & Percentage (\%) \\
\hline \multirow{4}{*}{ Body mass index } & \multirow[b]{2}{*}{ Day work } & Normal & 86.2 \\
\hline & & Overweight & 13.8 \\
\hline & \multirow[t]{2}{*}{ Shift work } & Normal & 18.4 \\
\hline & & Overweight & 81.6 \\
\hline \multirow{4}{*}{ Waist-hip ratio } & \multirow{2}{*}{ Day work } & Normal & 83.1 \\
\hline & & Overweight & 16.9 \\
\hline & \multirow{2}{*}{ Shift work } & Normal & 19.7 \\
\hline & & Overweight & 80.3 \\
\hline
\end{tabular}

According to table 4, the percentage of overweight WHR and BMI was higher among shift workers than day workers.

The findings of this study revealed that $81.6 \%$ of shift workers had a BMI of higher than 25 and $80.3 \%$ of shift workers had a WHR of higher than 0.90 . Moreover, $86.2 \%$ of day workers had a BMI of less than 25 and $83.1 \%$ of day workers had a WHR of less than 0.90 .
One-way ANOVA showed that age $(\mathrm{P}=$ $0.040)$ and work experience $(\mathrm{P}=0.040)$ had a significant relationship with BMI and WHR among day workers. One-way ANOVA results also showed that age $(\mathrm{P}=0.001)$ and work experience $(\mathrm{P}=0.001)$ had a significant relationship with BMI and WHR among shift workers.

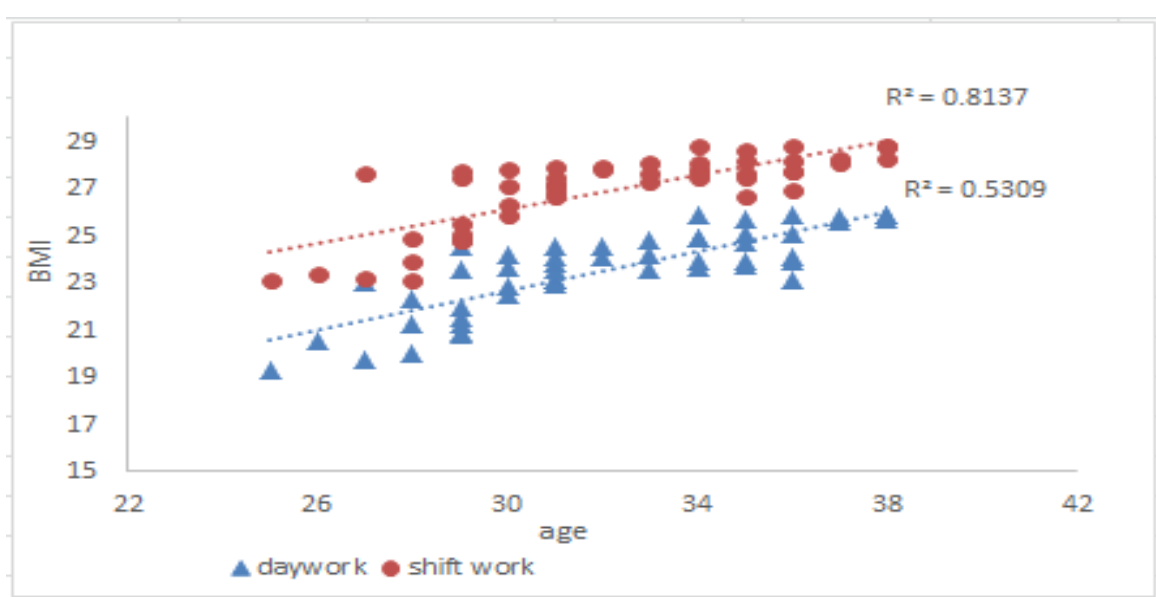

Figure 1: Linear regression (scatter plot) of age with body mass index in day and shift workers 
According to figures 1 and 2, linear regression (scatter plot) showed that with increasing age and work experience, little change was observed in BMI of day workers, but a rapid change was observed in BMI of shift workers.

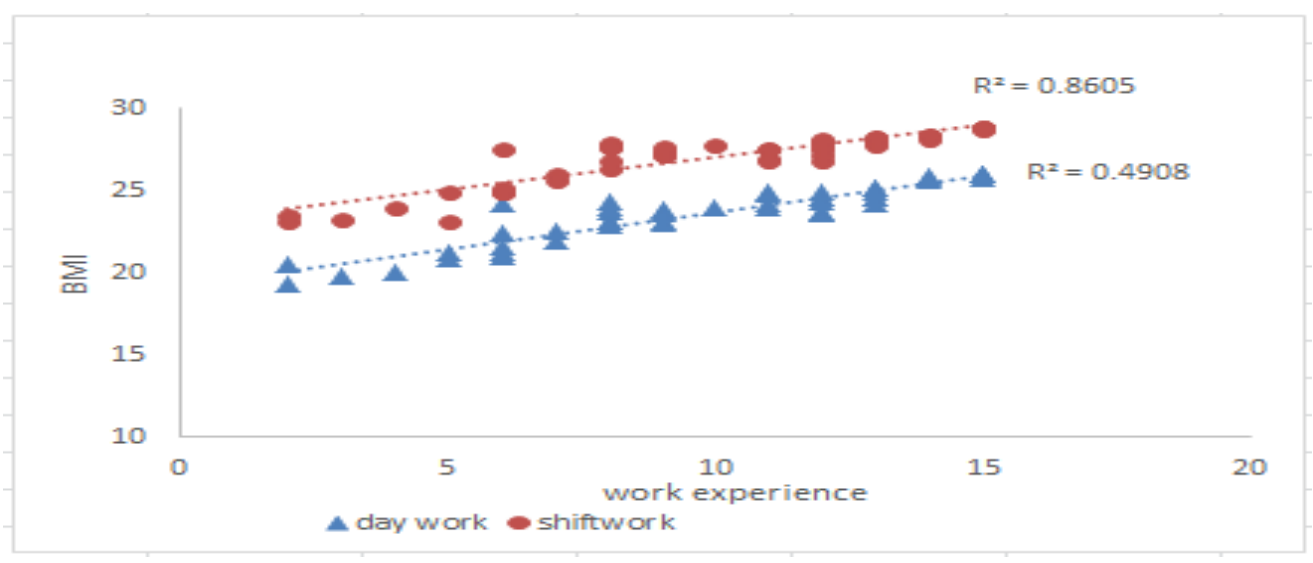

Figure 2: Linear regression (scatter plot) of work experience with body mass index of day and shift workers

According to figures 3 and 4, linear regression (scatter plot) showed that with increasing age and work experience, little change was observed in WHR of day workers, but a rapid change was observed in WHR of shift workers.

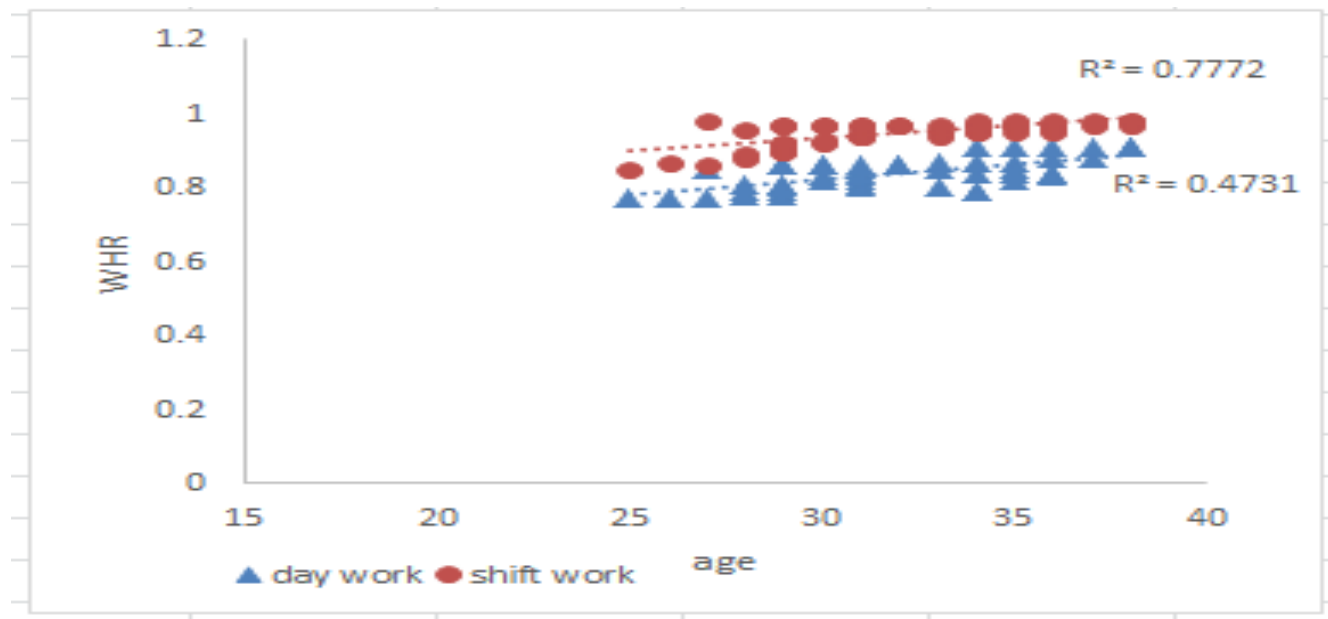

Figure 3: Linear regression (scatter plot) of age with waist-hip ratio in day and shift workers

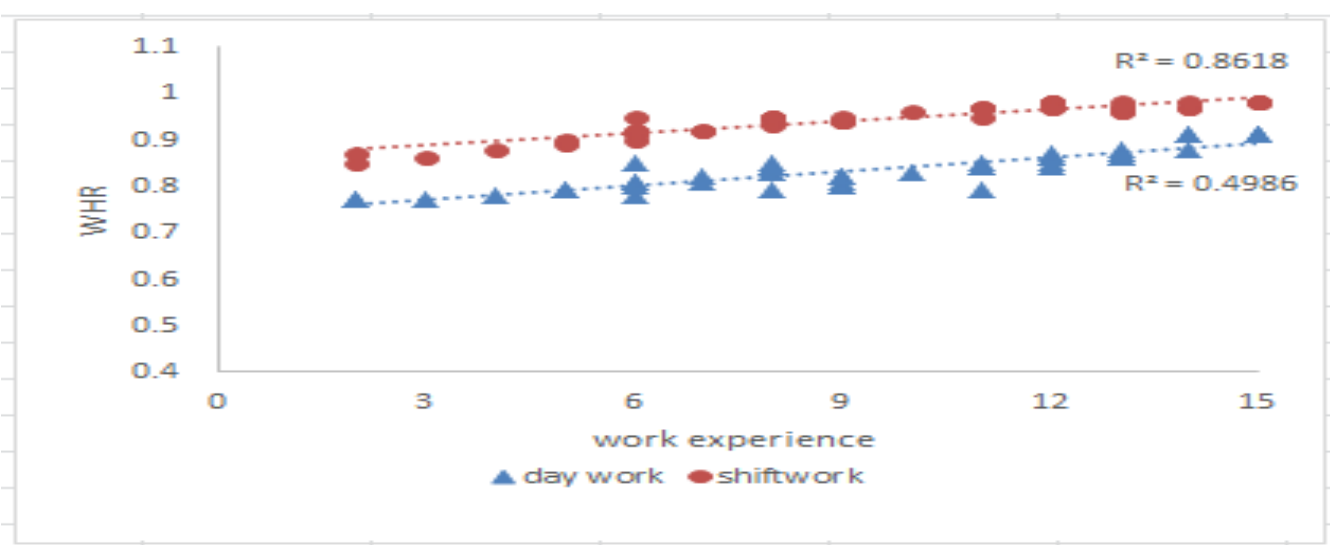

Figure 4: Linear regression (scatter plot) of work experience with waist-hip ratio of day and shift workers 


\section{Discussion}

Today, with the rapid growth of technology, increasing rate of production in military departments, and establishment of 24-hour centers such as military centers, shift work has become an inevitable element of many occupational activities. Shift work can cause disturbances in the body's natural cycle among night workers and shift workers. Shift work disrupts sleep among night workers and may also have an impact on the duration of their illness. In addition, considerable evidence indicates that shift workers suffer from physical and mental disorders. Obesity is a health problem that may cause other diseases. One of the risk factors obesity is shift work (19). Mean body weight, waist circumference, hip circumference, BMI, and WHR of shift workers were higher than day workers. According to the linear regression graphs, BMI and WHR of the shift workers changed more than that of the day workers. Ishizaki et al. investigated the influence of work characteristics on BMI and WHR in Japan and concluded that the BMI of shift workers was higher than day workers (20). This finding confirmed the present study findings. Lorenzo et al. studied the effect shift work on BMI and found that shiftwork has impact on weight, BMI, and waist circumference that confirmed the findings of the present study (21). Morikawa et al. showed that overweight among shift workers was more than the day workers, which is consistent with the results of this study (22). The relationship between shift work and obesity has been observed in longitudinal studies such as the studies by Niedhammer and Biggi. Shift work has been associated with a range of health problems including an increased risk of diabetes, heart disease, and stroke $(23,24)$. Antunes et al. investigated the effect of shift work on BMI and WHR concluded the difference was significant in waist circumference and BMI of shift workers than day works, which was consistent with the results of this study (25). The results of this study showed that with increasing age and work experience, rapid changes were observed in BMI and WHR, which was in agreement with the results of the study by Suwazono et al. (26). Moreover, the results of the study by Gholami Fesharaki et al. showed that with increasing age and work experience, the rates of obesity and BMI also increased that confirms the results of this study (27).

Khademian et al. investigated the relationship between night work and nurses' anthropometric indices and concluded that shift work has an incremental impact on BMI, WHR, and abdominal circumference (28). In the present study, BMI and waist circumference of shift workers were higher than day workers. This finding was in agreement with the findings of the study by Khademian et al. (28). Zayeri et al. assessed the relationship between shift work and BMI in petrochemical staff (29). They found a significant increase in BMI of all shift workers. Furthermore, the average annual trend of BMI in shift workers was about 0.12 $\mathrm{kg} / \mathrm{m}^{2}$ higher than day workers, which confirms the findings of the present study (29). Thus, interventions such as exercise after shift work to prevent overweight and obesity, avoidance of long duration of shift work, lack of consumption of heavy and fatty foods that cause drowsiness and loss of functionality and sugar-rich products such as soft drinks, sugar, sweets, and sugary drinks, job rotation, and consumption of lean meat, especially fish, vegetables and salads, whole grains, and lowfat yogurt, in shift workers have been suggested (30).

The limitation of this study was the lack of opportunity to utilize a larger sample size.

\section{Conclusion}

The results point to the need to consider shift and night work in obesity control programs at the workplace. The results of this study showed a direction significant correlation between shift work, and BMI and WHR. The findings of this study showed that shift work 
increased the risk of overweight and obesity. Increased BMI and WHR are the cause of disease and require intervention measures.

\section{Acknowledgments}

The present study was funded by the studied military center. The authors would like to thank all who participated in this research project and Mr Ghasemi for his assistance.

Conflict of interest: None declared.

\section{References}

1. Wang XS, Armstrong MEG, Cairns BJ, Key TJ, Travis RC. Shift work and chronic disease: the epidemiological evidence. Occup Med 2011; 61(2):78-89.

2. Bøggild H, Knutsson A. Shift work, risk factors and cardiovascular disease. Scand J Work Environ Health 1999; 25(4):85-99

3. Knutsson A. Health disorders of shift workers. Occup Med 2003; 53(2):103-8.

4. Bekkers MB, Koppes LL, Rodenburg W, van Steeg H, Proper KI. Relationship of night and shift work with weight change and lifestyle behaviors. J Occup Environ Med 2015; 57(4):e37-44.

5. Saksvik IB, Bjorvatn B, Hetland H, Sandal GM, Pallesen S. Individual differences in tolerance to shift work--a systematic review. Sleep Med Rev 2011; 15(4):221-35.

6. Bellanger TM, Bray GA. Obesity related morbidity and mortality. J La State Med Soc 2005; 157(Spec 1):S42-9.

7. Lenz M, Richter T, Muhlhauser I. The morbidity and mortality associated with overweight and obesity in adulthood: a systematic review. Dtsch Arztebl Int 2009; 106(40):641-8.

8. Van Drongelen A, Boot CR, Merkus SL, Smid T, van der Beek AJ: The effects of shift work on body weight change - a systematic review of longitudinal studies. Scand J Work Environ Health 2011; 37(4):263-75.

9. Kivimäki M, Kuisma P, Virtanen M, Elovainio M. Does shift work lead to poorer health habits? a comparison between women who had always done shift work with those who had never done shift work. Work Stress 2001; 15(1):3-13.

10. Heath G, Roach GD, Dorrian J, Ferguson SA, Darwent D, Sargent C. The effect of sleep restriction on snacking behaviour during a week of simulated shiftwork. Accid Anal Prev 2012; 45 Suppl:62-7.

11. Morrow L, Verins I, Willis E. Mental Health and Work: Issues and Perspectives. Australia: Faculty of Health Sciences, Flinders University South Australia, The Australian Network for Promotion, Prevention and Early Intervention for Mental Health 2002. P.3-6.

12. Spiegel K, Tasali E, Penev P, Van Cauter E. Brief communication: sleep curtailment in healthy young men is associated with decreased leptin levels, elevated ghrelin levels, and increased hunger and appetite. Ann Intern Med 2004; 141(11):846-50.

13. Zhao I, Bogossian F, Song S, Turner C. The association between shift work and unhealthy weight: a cross-sectional analysis from the Nurses and Midwives' e-Cohort Study. J Occup Environ Med 2011, 53(2):153-8.

14. Chen JD, Lin YC, Hsiao ST. Obesity and high blood pressure of 12-hour night shift female clean-room workers. Chronobiol Int 2010; 27(2):334-44.

15. Antunes LC, Levandovski R, Dantas G, Caumo W, Hidalgo MP. Obesity and shift work: chronobiological aspects. Nutr Res Rev 2010; 23(1):155-68.

16. Dorrian J, Skinner N. Alcohol consumption patterns of shiftworkers compared with dayworkers. Chronobiol Int 2012; 29(5):610-8.

17. Eknoyan G. Adolphe Quetelet (1796-1874) the average man and indices of obesity. Nephrol Dial Transplant 2008; 23(1):47-51.

18. Swiss. World Health Organization. Waist cirmumference and waist hip ratio: Report of a WHO Expert Consultation. Geneve: World Health Organization; 2008 Dec.

19. Folkard S, Lombardi DA. Modeling the impact of the components of long work hours oninjuries and "accidents". Am J Ind Med 2006; 49(1):953-63.

20. Ishizaki M, Morikawa $Y$, Nakagawa H, Honda $\mathrm{R}$, Kawakami N, Haratani $\mathrm{T}$, et al. The influence of work characteristics on body mass index and waist to hip ratio in Japanese employees. Ind Health 2004; 42(1):41-9.

21. Di Lorenzo L, De Pergola G, Zocchetti C, L'Abbate N, Basso A, Pannacciulli N, et al. Effect of shift work on body mass index: results of a study performed in 319 glucosetolerant men working in a Southern Italian industry. Int J Obes Relat Metab Disord 2003; 27(11):1353-8.

22. Morikawa Y, Nakagawa H, Miura K, Soyama Y, Ishizaki M, Kido T, et al. Effect of shift work on body mass index and metabolic parameters. Scand J Work Environ Health 2007; 33(1):45-50. 
23. Niedhammer I, Lert F, Marne MJ. Prevalence of overweight and weight gain in relation to night work in a nurses' cohort. Int J Obes Relat Metab Disord 1996; 20(7):625-33.

24. Biggi N, Consonni D, Galluzzo V, Sogliani M, Costa G. Metabolic syndrome in permanent night workers.Chronobiol Int 2008; 25(2):44354.

25. Antunes LC, Jornada MN, Ramalho L, Loayza Hidalgo MP. Correlation of shift work and waist circumference, body mass index, chronotype and depressive symptoms. Arq Bras Endocrinol Metabol 2010; 54(7):652-6.

26. Suwazono Y, Dochi M, Sakata K, Okubo Y, Oishi M, Tanaka K, et al. A longitudinal study on the effect of shift work on weight gain in male Japanese workers. Obesity (Silver Spring) 2008; 16(8):1887-93.
27. Gholami Fesharaki M, Kazemnejad A, Zayeri F, Rowzati M, Akbari H. Relationship between shift work and obesity; a retrospective cohort study. Journal of Military Medicine 2012; 14(2):93-7.

28. Khademian Z, Saadat F, Hasanshahi S. Relationship between night work and nurses' anthropometric indices. Iran Journal of Nursing 2012; 25(76):77-84.

29. Zayeri F, Khadem Maboudi AA, Hassanzadeh H, Najafi Kahaki A, Salari M. Assessment of the relationship between shift work and body mass index in petrochemical staff using latent growth curve model. Daneshvar Medicine 2015. 22(117):74-84.

30. Kneginja DR, Jens A, Friederike S,Günter N. Health promotion and work: prevention of shift work disorders in companies. EPMA J 2010; 1(4):611-8.

31. 